\section{Relationship between the Amine Contents of the Two Adrenal Glands of the Cat}

WORKERS ${ }^{1}$ vary in their methods of calculating the adrenaline and noradrenaline content of adrenal glands. Some express them in micrograms per unit weight of gland, some in micrograms per gland and some even in micrograms per kilogram of bodyweight. Since, frequently, there is a difference between the weight of the left and of the right gland of each cat, it was thought desirable to determine whether the percentage of noradrenaline is the same in the two glands, and whether the total amine content is the same for both glands or whether the heavier gland contains more amine.

Both adrenal glands from thirty-six adult cats were dissected free of connective tissue, and $50 \mathrm{mgm} . /$ ml. extracts were prepared in $0.1 \mathrm{~N}$ hydrochloric acid. The adrenaline and noradrenaline content of each extract was assayed biologically, using the cat, blood pressure and nictitating membrane as test preparations. The results were calculated by the formula of Bülbring ${ }^{2}$. At least two determinations were made on each preparation and the results were treated statistically.

As can be seen from Fig. 1, the percentages of noradrenaline in the right and left glands are equal. From the thirty-six pairs of results the mean percentage of noradrenaline in the left gland was 44.5 per cent and in the right gland was 44.0 per cent. The correlation between the pair of glands is independent of the degree of methylation and of any difference in the weight of the two glands.

In some cats, the two adrenals may not vary by more than a few milligrams. However, in others the difference may be considerable. In this series of experiments the greatest absolute difference in weight was $52 \mathrm{mgm}$. and the greatest difference, expressed as a percentage, was $36 \cdot 4$ per cent. In other experiments ${ }^{3}$, absolute differences as great as $100 \mathrm{mgm}$. were observed.

As can be seen from Fig. 2, where the results from glands which differed in weight by more than 1 per cent are recorded, there is a much closer correlation between the amount of amine in the two glands when expressed as per gland than when expressed as per $100 \mathrm{mgm}$. of gland. This is true whether the difference in the weight of the two glands is small or large. Although only mean results are shown in the above two figures, the results from individual pairs of glands show the same picture.

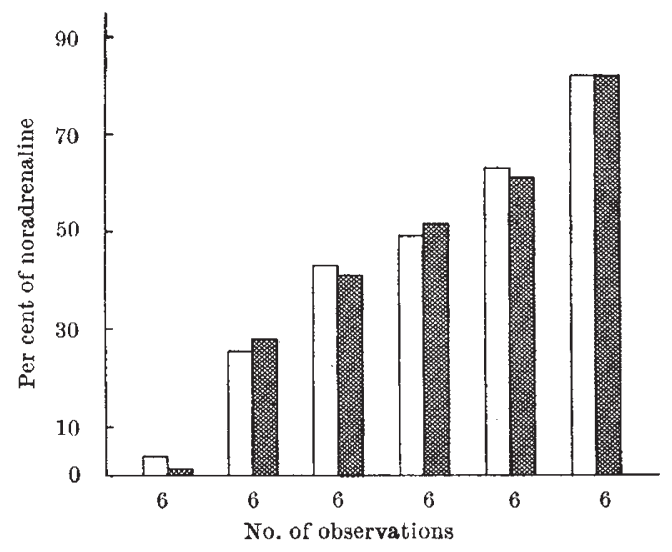

Fig. 1. Comparison of the percentage of noradrenaline in the left and right adrenal glands of the adult cat. The hatched area represents the left gland and the shaded area the right gland

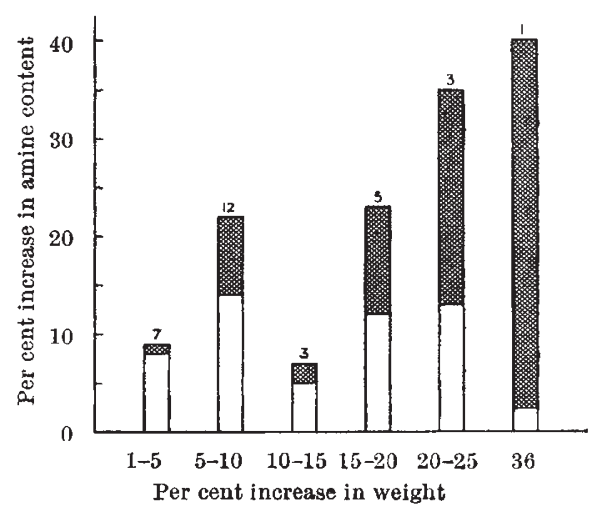

Fig. 2. Comparison of the amine contents of the two adrenal glands of the cat. The shaded area represents the difference in the amine content of the right and left glands, expressed as per $100 \mathrm{mgm}$. of gland, and the clear area represents the difference expressed as per gland. In all cases the diference is expressed as a percentage increase. The number above each column obtained

Thus it may be concluded that, in the cat, the adrenaline and noradrenaline content of the two adrenal glands should be calculated as per gland and not as per unit weight of gland. This is of importance when one gland of the animal is used as a control and the effects of drugs on the other are studied ${ }^{3}$.

\section{K. R. BUTTERWORTH*} Monica MANN

Department of Pharmacology,

School of Pharmacy,

University of London,

17 Bloomsbury Square, London, W.C.1.

Feb. 18.

* Present address: Department of Pharmacology, St. Mary's Hospital Medical School, London, W.2.

${ }^{1}$ Crawford, T. B. B., and Outschoorn, A. S., Brit. J. Pharmacol.

6,8 (1951). Hökfelt, B, and McLean, J., Acta physiol. Scand. Bülbring, E., Brit. J. Pharmacol., 4, 234 (1949).

3 Butterworth, K. R., and Mann, M. (to be published).

\section{Comparative Hyperfibrinogenæmic Action of D- and L-Adrenaline}

IN a previous work on the hyperfibrinogenæmic effect of several sympathomimetic amines, it was reported ${ }^{1}$ that adrenaline, when injected subcutaneously into the rat, has the highest activity in increasing blood plasma fibrinogen. We have now compared the activity of $\mathrm{D}$ - and $\mathrm{L}$-adrenaline in relation to the hyperfibrinogenæmic response. After a preliminary experiment to find roughly the relative hyperfibrinogenæmic effect of the two forms of adrenaline, the following experiment was carried out. Forty female albino rats of 150-200 gm. body-weight were divided by randomization into four groups of ten rats each. Two groups received subcutaneously respectively 0.03 and $0.06 \mathrm{mgm}$. of adrenaline (expressed as base)/100 gm. body-weight. The other two groups were injected respectively with 1 and $2 \mathrm{mgm}$. of $\mathrm{D}$-adrenaline (base). $24 \mathrm{hr}$. later, the rats were bled from the aorta under pentobarbitonesodium anæesthesia (4 mgm./100 gm. body-weight) using syringes coated with 'Dry Film 9987', clotting being prevented by the addition of $0.01 \mathrm{ml}$. of 30 per 